\title{
Determination of Incidental Finding in Salivary Glands in Adult Sudanese Population using Ultrasonography
}

Mohammed Amir Hassan ${ }^{1 *}$, Awadia Gareeballah Suliman ${ }^{1,2}$, Ahmed Abdelrahim Mohammed ${ }^{1}$, Ragaa Ahmed Aburaida ${ }^{1}$, Mowada Burai Mohamed ${ }^{1}$, Naglaa Elsir Mohammed $^{3}$

${ }^{1}$ Faculty of Radiological Sciences and Medical Imaging, Alzaiem Alazhari University, Khartoum, Sudan

${ }^{2}$ Department of Diagnostic Radiologic Technology, Faculty of Applied Medical Sciences, Taibah University, Al-madinah Al-Munawarah, King Saudi Arabia

${ }^{3}$ Al-Ghad International College of Applied Medical Sciences, Kingdom of Saudi Arabia

DOI: $10.36347 /$ sjams.2020.v08i05.012

| Received: 03.05.2020 | Accepted: 11.05.2020 | Published: 14.05.2020

*Corresponding author: Mohammed Amir Hassan

Abstract

Original Research Article

This was descriptive study done in Khartoum state -Sudan, to determine the incidental finding in salivary glands in adult Sudanese population using utrasonography, the sampling includes 254 patients came to area of the study in age ranged $18-53$ years, $(59.4 \%)$ of them were female, verbal ethical approval taken from each of them, then ultrasound scanning of salivary gland was performed, the data collected by data sheet including the study variables which are age, gender, size and incidental ultrasound finding then analysed by SPSS version 16, frequency and percentage are calculated then chi square test were performed to assess correlation between study variables, the study found that $2.8 \%$ of the patients had an incidental finding during ultrasound scan, most finding present is parotitis due to mumps ( $0.8 \%)$, followed by Sjo"gren syndrome, sialolithiasis, LNs, lesion+ LNs and lesion $(0.4 \%)$ for each of them respectively. The study concluded that ultrasound can detect and determined the incidental abnormalities on salivary gland and also differentiate between them.

Keywords: Incidental sialolithiasis Sjo“gren utrasonography.

Copyright @ 2020: This is an open-access article distributed under the terms of the Creative Commons Attribution license which permits unrestricted use, distribution, and reproduction in any medium for non-commercial use (NonCommercial, or CC-BY-NC) provided the original author and source are credited.

\section{INTRODUCTION}

There are many diseases affecting salivary gland such as inflammation, stones and tumours. Ultrasound is first modality to assess these diseases and differentiate between them. In inflammatory condition when it is acute inflammation the glands appears as an enlarged, hypoechoic with increased blood flow; they may contain multiple small, oval, hypoechoic areas and associated lymphadenopathy in some cases but in chronic inflammation the glands are normal sized or smaller, hypoechoic, and inhomogeneous with normal blood flow. Sialolithiasis appears as hyperechoic lines or foci with distal acoustic shadowing. In advance cases of Sjo"gren syndrome the gland appears as inhomogeneous with multiple scattered small, ovals, hypoechoic or anechoic areas, well defined and increased blood flow. Pleomorphic adenomas appear as hypoechoic, well-defined and lobulated lesions with posterior acoustic enhancement and may contain calcifications; Warthin tumors are usually appear as oval, hypoechoic, well-defined lesions that often contain anechoic areas and high vascularity. Malignant neoplasms of the salivary glands may appear irregular shapes and borders, ill-defined and a hypoechoic inhomogeneous structure or may overlap a benign appearance. Salivary gland cysts appear as well-defined margins anechoic with posterior acoustic enhancement with no internal vascularity [1].

\section{OBJECTIVE}

To determine the incidental finding in salivary gland detected by ultrasound in adult Sudanese using high frequency ultrasonography.

\section{MeTHODOLOGY}

This was descriptive cross sectional study done in Khartoum state Sudan in Alhikma POLYCLINICS 1 in the period from 2018 to 2020, the sampling includes 254 adult Sudanese population came to ultrasound department of other purpose of scanning rather than for salivary gland, after ethical approval was taken from each patients, ultrasound for parotid and submandibular gland is performed using Ezoate mylap 40 with $7.5 \mathrm{MHz}$ high frequency linear array probe to determine the incidental abnormalities in salivary gland, the patient is examined in reclining position, neck 
extended ,both side are examine in longitudinal and transverse plane, the data collected using data collection sheet including the study variables which are patient age ,gender and ultrasound finding in the gland each finding is assess in two orthogonal planes, the whole neck is scan to excludes associated lymphadenopathy, then analyzed by SPSS version 16, frequency and percentage are performed then cross tabulation is performed to determine the relationship between age, gender and ultrasound finding ( $\mathrm{p}$ value $<0.05$ consider significant), all patients with known pathology of salivary gland excluded.

\section{RESUltS AND DisCUSSION}

Concerning the age of the patients the study done in age ranged from 18-53 years, more than halve of them $(56.7 \%)$ in age ranged $18-27$ years, followed by $(24.4 \%)$ in age ranged $38-47$ years (Table 1 ).

Table-1: Frequency distribution of age of the patients

\begin{tabular}{|l|r|r|r|r|}
\hline Age lyears & \multicolumn{1}{|c|}{ Frequency } & \multicolumn{1}{|c|}{ Percent } & Valid Percent & Cumulative Percent \\
\hline $18-27$ & 144 & 56.7 & 56.7 & 56.7 \\
\hline $28-37$ & 33 & 13.0 & 13.0 & 69.7 \\
\hline $38-47$ & 62 & 24.4 & 24.4 & 94.1 \\
\hline $48-53$ & 15 & 5.9 & 5.9 & 100.0 \\
\hline Total & 254 & 100.0 & 100.0 & \\
\hline
\end{tabular}

More than halve of them were female gender (59.4\%). Table (2)

Table-2: Frequency distribution of gender

\begin{tabular}{|l|r|r|r|r|}
\hline Gender & Frequency & \multicolumn{1}{c|}{ Percent } & Valid Percent & Cumulative Percent \\
\hline Female & 151 & 59.4 & 59.4 & 59.4 \\
\hline Male & 103 & 40.6 & 40.6 & 100.0 \\
\hline Total & 254 & 100.0 & 100.0 & \\
\hline
\end{tabular}

Out of 254 cases the study found that $(2.8 \%)$ had an incidental finding in salivary gland, on the other hand E.A. Egorova et al. in our study of differential radiodiagnosis of salivary gland masses state that on $(2.5 \%)$ of patients the mass is and incidental finding with no manifestation [2]. K. Onda et al. stated that an incidental finding in salivary gland is about $4 \%$ in patients came for thyroid scanning, their incidence is higher this may due to larger sampling in our study[3] Table (3).

Table-3: Frequency distribution of presence of an incidental finding

\begin{tabular}{|l|r|r|r|r|}
\hline Finding & \multicolumn{1}{|c|}{ Frequency } & \multicolumn{1}{c|}{ Percent } & Valid Percent & Cumulative Percent \\
\hline Yes & 7 & 2.8 & 2.8 & 2.8 \\
\hline No & 247 & 97.2 & 97.2 & 100 \\
\hline Total & 254 & & & \\
\hline
\end{tabular}

The study demonstrated that the most common incidental finding was parotitis due to mumps two cases $(0.8 \%)$, followed by Sjo "gren syndrome, sialolithiasis, LNs, lesion+ LNs and lesion each of them 1 case $(0.4 \%$, K. Onda et al. found that Sjo gren syndrome is more common incidental finding followed by sialadenitis and tumors. On the other hand no previous studies done to determine an incidental finding in salivary gland during thyroid ultrasound [3].
For diagnosis of thyroid disorder by ultrasound in general Patange NA et al. stated sialolithiasis is more common pathology as in this study Lesion and parotitis due to mumps are more common, Schurawitzki et al. found that the most common pathology was lesion followed by sialadenitis $[4,5]$. Table (4)

Table-4: Frequency distribution of incidental finding

\begin{tabular}{|l|r|r|r|r|}
\hline Finding & Frequency & Percent & \multicolumn{1}{c|}{$\begin{array}{c}\text { Valid } \\
\text { Percent }\end{array}$} & $\begin{array}{c}\text { Cumulative } \\
\text { Percent }\end{array}$ \\
\hline Lesion & 1 & .4 & 14.3 & 14.3 \\
\hline parotitis due to mumps & 2 & .8 & 28.6 & 42.9 \\
\hline Lt parotid LNs & 1 & .4 & 14.3 & 57.1 \\
\hline Lesion + LNs & 1 & .4 & 14.3 & 71.4 \\
\hline Sjo“gren syndrome & 1 & .4 & 14.3 & 85.7 \\
\hline Stones & 1 & .4 & 14.3 & 100.0 \\
\hline Total & 7 & 2.8 & 100.0 & \\
\hline
\end{tabular}


Concerning the size of the parotid gland the study found that $98.8 \%$ of those patients have normal gland size while $1.2 \%$ had an enlarged gland due to parotitis and Sjo"gren syndrome. The size of the gland in case of Sjo"gren syndrome was $10.42 \mathrm{~cm}^{3}$ and in parotitis is $8.16 \mathrm{~cm}^{3}$. Table $(5-6)$

Table-5: Frequency distribution of gland size

\begin{tabular}{|l|r|r|r|r|}
\hline Parotid Volume & \multicolumn{1}{|c|}{ Frequency } & Percent & Valid Percent & Cumulative Percent \\
\hline normal & 251 & 98.8 & 98.8 & 98.8 \\
\hline enlarged & 3 & 1.2 & 1.2 & 100.0 \\
\hline Total & 254 & 100.0 & 100.0 & \\
\hline
\end{tabular}

Table-6: Cross tabulation between gland size and finding

\begin{tabular}{|l|l|l|l|l|l|l|l|}
\hline \multirow{2}{*}{ Size } & \multicolumn{9}{c|}{ Finding } & \multirow{2}{*}{ Total } \\
\cline { 2 - 8 } & lesion & Parotitis due to mumps & Lt parotid LNs & lesion+ LNs & Sjögren syndrome & Stones & \\
\hline Normal & $1(3.98 \mathrm{~cm} 3)$ & 0 & $1(2.65 \mathrm{~cm} 3)$ & $1(4.18 \mathrm{~cm} 3)$ & 0 & $1(1.82 \mathrm{~cm} 3)$ & 4 \\
\hline Enlarged & 0 & $2(8.16 \mathrm{~cm} 3)$ & 0 & 0 & $1(10.42 \mathrm{~cm} 3)$ & 0 & 3 \\
\hline Total & 1 & 2 & 1 & 1 & 1 & 1 & $7(5.62 \mathrm{~cm} 3)$ \\
\hline
\end{tabular}

The study found that no significant correlation between age, gender and incidental finding in salivary gland $\mathrm{P}$ value more than 0.05 . Concerning age group the study revealed that among the patients with incidental finding 18-27 years age are more affected by salivary gland pathology $(42.85 \%)$, this result disagree with Patange NA et al. 2017 whom stated 41-50 years more affected by pathology of the gland. In this study the pathology of salivary gland was more common in male than female $(57.14 \%)$, this result agree with Patange NA et al. and disagree with K. Onda et al. whom found the incidental detected more common in female in our studies larger sample volume is assess compare to this study[3-4] Table (7-8).

Table-7: Cross tabulation between age and findings

\begin{tabular}{|l|l|l|l|l|l|l|l|}
\hline \multirow{2}{*}{ Age } & \multicolumn{3}{l}{ Findings } & \multicolumn{2}{l|}{ Total } \\
\cline { 2 - 7 } & lesion & parotitis due to mumps & Lt parotid LNs & lesion+ LNs & Sjo“gren syndrome & stones & \\
\hline $18-27$ & 0 & 1 & 1 & 0 & 0 & 1 & 3 \\
\hline $28-37$ & 0 & 1 & 0 & 1 & 0 & 0 & 2 \\
\hline $38-47$ & 1 & 0 & 0 & 0 & 1 & 0 & 2 \\
\hline Total & 1 & 2 & 1 & 1 & 1 & 1 & 7 \\
\hline P value
\end{tabular}

Table-8: Cross tabulation between gender and findings

\begin{tabular}{|c|c|c|c|c|c|c|c|}
\hline \multirow{2}{*}{ Gender } & \multicolumn{6}{|c|}{ Findings } & \multirow{2}{*}{ Total } \\
\hline & lesion & parotitis due to mumps & Lt parotid LNs & lesion+ LNs & Sjo"gren syndrome & stones & \\
\hline Female & 1 & 0 & 1 & 0 & 1 & 0 & 3 \\
\hline Male & 0 & 2 & 0 & 1 & 0 & 1 & 4 \\
\hline Total & 1 & 2 & 1 & 1 & 1 & 1 & 7 \\
\hline
\end{tabular}

\section{Conclusion}

The study concluded that high frequency ultrasound determines different finding in salivary gland, differentiate most of them such as sialolithiasis, inflammation, Sjo"gren syndrome, the most common abnormalities detected in salivary gland are inflammation and lesion, the male affected by salivary abnormalities more than male.

\section{RECOMMENDATIONS}

The study recommended that scanning of salivary gland is important during neck and thyroid scanning to exclude incidental findings and beside that further studies should be done with larger sampling and more duration to assess the incidental finding in salivary gland.

\section{ACKNOWLEDGEMENT}

The authors send thanks to all in Alhikma POLYCLINICS 1 for granted an ethical approval and helping us in data collection.

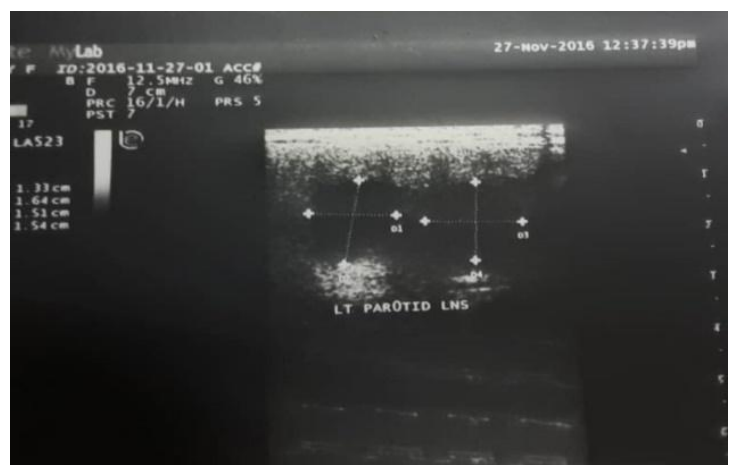

Fig-1: 26 years female with left parotid LNs associated with lesion 


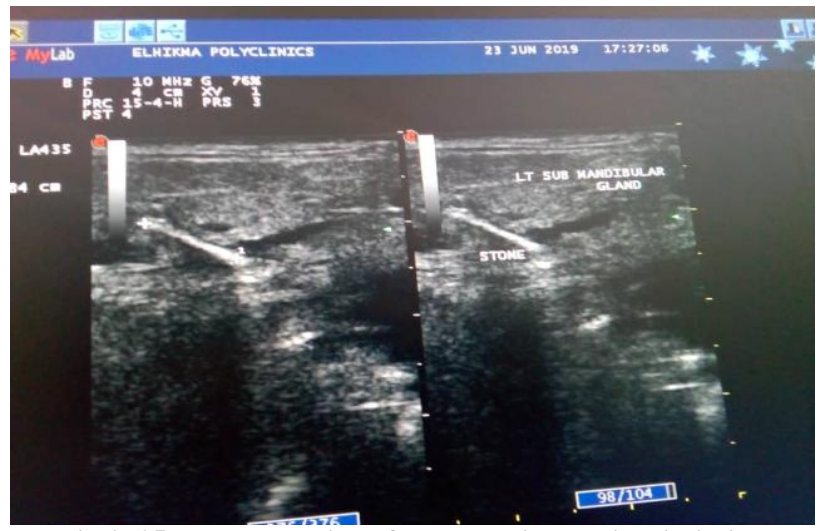

Fig-2: 25 years male with left submandibular sialolithiasis

\section{REFERENCES}

1. Ewa J. Bialek, Wieslaw Jakubowski, Piotr Zajkowski, Kazimierz TSzopinski, Antoni Osmolski. US of the Major Salivary Glands: Anatomy and Spatial Relationships, Pathologic
Conditions, and Pitfalls. Radio Graphics. 2006; 26:745-763.

2. Egorova EA, Smyslenova MV, Obinya NP, Faskhutdinov DK. Differential radiodiagnosis of salivary gland masses. Современные технологии в медицине. 2013;5(3 (eng)).

3. Kanna Onda, Takahiro Fukuhara, Eriko Matsuda, Ryohei Donishi, Yasuaki Hirooka, Hiromi Takeuchi. Impact of Screening for Salivary Gland by Ultrasonography. Yonago Acta Medica. 2020;63(1):42-46.

4. Neeraj A. Patange, Suresh V. Phatak. Ultrasound and Doppler evaluation of salivary gland pathology. Int J Res Med Sci. 2017 Jan;5(1):79-82

5. Schurawitzki H, Gritzmann N, Fezoulidis J, Karnel F, Kramer J. Value and indications for highresolution real-time sonography in non-tumour salivery gland diseases. Rofo. 1987;146(5):527-31. 